\title{
The Uses of Theory, Concepts and Comparison in Historical Sociology
}

\author{
VICTORIA E. BONNELL
}

University of California, Berkeley

The sociological study of history has only recently achieved recognition in American sociology. Although historical research occupied an important place in the nineteenth-century European sociological tradition, ${ }^{1}$ American scholars long accepted a disciplinary division relegating the study of the past to historians, while reserving contemporary subjects for sociological investigation. The field of historical sociology first witnessed a revival in the 1950s with the publication of Reinhard Bendix's Work and Authority in Industry (1956) and Neil Smelser's Social Change in the Industrial Revolution (1959). ${ }^{2}$ During these years, a small chorus of voices called for a more historical approach to sociological problems and closer cooperation between the two disciplines. ${ }^{3}$

The interest in historical-sociological research increased steadily in the

This paper was originally presented, in somewhat different form, at the Annual Meeting of the American Historical Association in December 1978. The author wishes to thank the many friends and colleagues who provided comments on this and earlier drafts of the essay.

${ }^{1}$ For a discussion of the nineteenth-century origins of the historical-comparative method, see Kenneth E. Bock, The Acceptance of Histories. Toward a Perspective for Social Science (Berkeley and Los Angeles: University of California Press, 1956).

${ }^{2}$ Reinhard Bendix, Work and Authority in Industry. Ideologies of Management in the Course of Industrialization (New York: John Wiley and Sons, 1956); Neil J. Smelser, Social Change in the Industrial Revolution. An Application of Theory to the British Cotton Industry (Chicago: University of Chicago Press, 1959). These two studies do not exhaust the list of sociological works with an historical orientation published in the 1950s. Other significant contributions include Seymour Martin Lipset, Agrarian Socialism. The Cooperative Commonwealth Federation in Saskatchewan (Berkeley and Los Angeles: University of California Press, 1950); Wolfram Eberhard, Conquerors and Rulers. Social Forces in Medieval China (Leiden, Netherlands: E.J. Brill, 1952); Barrington Moore, Jr., Terror and Progress (Cambridge: Harvard University Press, 1956); Robert N. Bellah, Tokugawa Religion: The Values of Pre-Industrial Japan (Glencoe, Ill.: The Free Press, 1957).

${ }^{3}$ See, for example, Seymour Martin Lipset, "A Sociologist Looks at History," Pacific Sociological Revien, I:1 (Spring 1958). Among historians, Sylvia Thrupp was the foremost advocate during this decade of a rapprochement between history and sociology. She went on to found Comparative Studies in Society and History in 1958. Thrupp's essays from this period $0010-4175 / 80 / 2209-0500 \$ 2.00$ (C) 1980 Society for Comparative Study of Society and History 
1960s, a decade that marked the appearance of Bendix's Nation Building and Citizenship (1964), Charles Tilly's The Vendée (1964) and Barrington Moore's Social Origins of Dictatorship and Democracy (1966). ${ }^{4}$ Yet, it was not until the 1970s that the sociological study of history achieved full status within the discipline, symbolized by the awarding of the prestigious Sorokin prize to sociologists with an historical orientation in 1976 and again in 1977.5

The growing field of historical sociology has generated new methodological approaches and problems that have not yet received the attention they deserve. ${ }^{6}$ The purpose of this essay is to explore some of these issues, beginning with a brief consideration of the contrasting methodological perspectives in the two disciplines. I will argue that the methodological foundations of historical-sociological research must be sought, first, in the way theories and concepts are formulated and applied to historical problems. Two types of research strategy will be discussed, involving the mediation of history by theory and the mediation of history by concepts. A related and equally important methodological component of historicalsociological research is the use of comparison. Here, too, a binary division can be discerned between "illustrative" and "analytical" forms of comparative study.

In examining these issues, I will focus on selected works by Bendix, Moore, Smelser, Tilly, and Wallerstein. Methodologically and substantively diverse, these five leading historical sociologists have made significant

have recently been reissued in Raymond Grew and Nicholas H. Steneck, eds., Society and History. Essays by Sylvia L. Thrupp (Ann Arbor: University of Michigan Press, 1977).

${ }^{4}$ Reinhard Bendix, Nation-Building and Citizenship: Studies in our Changing Social Order (New York: John Wiley and Sons, 1964); Charles Tilly, The Vendée (Cambridge: Harvard University Press, 1964); Barrington Moore, Jr., Social Origins of Dictatorship and Democracy. Lord and Peasant in the Making of the Modern World (Boston: Beacon Press, 1966). A number of other important historical-sociological studies appeared in the 1960s, including Guenther Roth, The Social Democrats in Imperial Germany. A Study in Working-Class Isolation and National Integration (Totawa: Bedminster Press, 1963); S.N. Eisenstadt, The Political Systems of Empires (New York: The Free Press of Glencoe, 1963); Guy E. Swanson, Religion and Regime. A Sociological Account of the Reformation (Ann Arbor: University of Michigan Press, 1967).

${ }^{5}$ In 1976, Jeffrey Paige and Robert Bellah were co-recipients of the Sorokin Prize; Immanuel Wallerstein was awarded the prize in 1977.

${ }^{6}$ The literature on methodological aspects of historical/comparative sociology is sparse indeed. Some interesting thoughts on the subject can be found in Daniel Chirot, "Introduction: Thematic Controversies and New Developments in the Use of Historical Materials by Sociologists," Social Forces 55: 2 (December 1976); Bruce C. Johnson, "Missionaries, Tourists and Traders: Sociologists in the Domain of History," unpublished paper, 1979; Timothy McDaniel, "Meaning and Comparative Concepts," Theory and Society, 6 (July-November 1976); Arthur L. Stinchcombe, Theoretical Models in Social History (New York: Academic Press, 1978); Ivan Vallier, "Empirical Comparisons of Social Structure: Leads and Lags," in Ivan Vallier, ed., Comparative Methods in Sociology. Essays on Trends and Applications (Berkeley, Los Angeles, London: University of California Press, 1971). For additional bibliographical references on the subject of methodology, see note 7 . 
and influential contributions to the field. ${ }^{7}$ An analysis of their uses of theory, concepts, and comparison will enhance our understanding and appreciation of the sociological study of history.

The facile distinctions that are sometimes drawn between the methodology of sociologists and historians (e.g., a deductive versus inductive approach ${ }^{8}$ or the use of secondary as opposed to primary material ${ }^{9}$ ) do not take into account the complexity and variety of scholarship in both disciplines during the past several decades. The application of quantitative techniques to historical research ${ }^{10}$ has actually brought the disciplines closer together and established an important if limited area of cooperation. But this development and the wishful thinking of advocates of "intellectual unity" " cannot produce disciplinary convergence. The fact is that practitioners of the two disciplines persist in adopting divergent concepts and procedures in designing a research strategy. And while these divergences may derive from a difference merely in emphasis and degree, they are nevertheless indicative of distinctive disciplinary orientations.

The first step in designing a research strategy - the selection of problems

${ }^{7}$ It is noteworthy that each of these scholars has written about methodology per se. See, for example. Neil J. Smelser, Comparative Methods in the Social Science and Essays in Sociological Explanation; Barrington Moore, Jr., "Strategy in Social Science," in Barrington Moore, Jr., Political Power and Social Theory; Reinhard Bendix, "Concepts and Generalizations in Comparative Sociological Studies," American Sociological Review, 28:4 (August 1963), pp. 532-39 and Reinhard Bendix and Bennett Berger, "Images of Society and Problems of Concept Formation in Sociology," in Reinhard Bendix, Embattled Reason. Essays on Social Knowledge; Terence K. Hopkins and Immanuel Wallerstein, "The Comparative Study of National Societies," Social Science Information, VI-5 (October 1976), pp. 25-28. Charles Tilly has written extensively about methodology in his recent works. See, for example, Ch. 8 and Appendices 1-4 in From Mobilization to Revolution (Reading, Mass.: 1978). Additional work by Tilly on this subject is cited in Charles Tilly, Louise Tilly, and Richard Tilly, The Rebellious Century 1830-1930 (Cambridge: Harvard University Press, 1975), p. 341.

${ }^{8}$ The terms "deductive" and "inductive" will be used in the essay to refer to a process of reasoning that proceeds from a priori propositions to empirical evidence (deductive) or conversely, from empirical evidence to the formulation of propositions (inductive). Social science research is seldom based purely on either deductive or inductive reasoning, but a proclivity toward one or the other can nevertheless be discerned in specific works. Smelser's methodology in Social Change in the Industrial Revolution represents an unambiguous case of formal deductive reasoning, with inferences drawn from general sociological theory. Some of the other works discussed below, such as the Tillys' Rebellious Century, formulate analytical propositions mainly, though not exclusively, on the basis of accumulated empirical data.

${ }^{9}$ I am using the term "primary" to refer to any source that came into existence contemporaneously with the event or phenomenon under investigation, for example, a police report of a demonstration, newspaper accounts, a documentary record of any kind, census data or other statistical material collected at the time. The term "secondary" is used here to refer to accounts compiled on the basis of primary sources.

${ }^{10}$ See Val R. Lorwin and Jacob M. Price, eds., The Dimensions of the Past. Materials, Problems, and Opportunities for Quantitative Work in History (New Haven and London: Yale University Press, 1972).

${ }^{11}$ Immanuel Wallerstein has argued, for example, that "to reify the motives of scholars in doing particular research into two disciplines - the first history, the second social science-is to give misleading substance to the accidental and passing, and to miss the intellectual unity of 
for study-reveals the contrasting approaches in the two disciplines. Smelser aptly describes the difference:

In their methods of identifying problems for study, sociologists and historians ... display different, though overlapping, emphases. A historical problem, generally speaking, is rooted in and emerges from the logic of events of a given place and period; for example, why did the French monarchy and aristocracy become so unresponsive to demands for social reform during the eighteenth century? By contrast, a sociological problem, generally speaking, tends to be rooted in and is generated by some conceptual apparatus; for example, what are the relations between blocked social mobility and social protest, illustrated in the eighteenthcentury French case? ${ }^{12}$

Sociologists and historians also differ in their willingness to undertake comparative analysis across national and temporal boundaries. Whereas it is virtually axiomatic among sociologists that this kind of comparison is both possible and fruitful (although there may be disagreement on the appropriate unit for comparison), many historians do not easily accept a comparative framework that extends beyond a single historical period, nation or culture. The reluctance to make the conceptual leap from one time and place to another is connected with the third point of difference between sociologists and historians, namely, their conceptions of theory and its relation to history.

Generalizations applied to empirical phenomena can be formulated on three levels: statements applicable to a phenomenon or phenomena in a single case; statements applicable to a phenomenon or phenomena in a class of cases, often described as middle-range theory; ${ }^{13}$ statements with universal applicability. Whereas historians are inclined to formulate generalizations of the first type, sociologists characteristically look for theories that conform to the second or third level of applicability.

the two enterprises." Immanuel Wallerstein, The Capitalist World-Economy (Cambridge, England: Cambridge University Press, 1979), p. x. See also Gareth Stedman Jones, "From Historical Sociology to Theoretical History," The British Journal of Sociology, 27:3 (September 1976).

${ }^{12}$ Neil J. Smelser, Essays in Sociological Explanation (Englewood Cliffs: Prentice-Hall, 1968), p. 35. Marxist historians constitute one major exception to this generalization. For an outstanding discussion of the Marxist approach, see Richard Johnson, "Thompson, Genovese, and Socialist-Humanist History," History Workshop, 6 (Autumn 1978) and "An Interview with E.P. Thompson" by Michael Merrill, Radical History Review 3: 4 (Fall 1976).

${ }^{13}$ Merton has labelled the second level of theory "middle range": "... [theories of the middle range] lie between the minor but necessary working hypotheses that evolve in abundance during day-to-day research and the all-inclusive systematic efforts to develop a unified theory that will explain all the observed uniformities of social behavior, social organization and social change. ... It is intermediate to general theories of social systems which are too remote from particular classes of social behavior, organization and change to account for what is observed and to those detailed orderly descriptions of particulars that are not generalized at all. Middle-range theory involves abstractions, of course, but they are close enough to observed data to be incorporated in propositions that permit empirical testing." Robert K. Merton, Social Theory and Social Structure (New York: The Free Press, 1968), p. 38. 
The logic of sociological theory-building leads directly to comparative study. A single illustrative or paradigmatic case can be used to test a theory of the second or third type, or to formulate new hypotheses, but the comparative method is required in order to establish with certainty that a theoretical proposition applicable to one case sustains its explanatory power when applied to additional cases. Thus, comparative analysis is an intrinsic part of the historical-sociological enterprise, although considerable diversity has accompanied its application. ${ }^{14}$

In general, sociologists not only aim for broader theoretical statements than do historians; they also tend to rely on a "more formal, explicitly conceptual apparatus that is more self-consciously selective of facts." 15 This is not to suggest that the historian proceeds without relying, consciously or unconsciously, on certain "preconceived concepts, assumptions, and suspected associations among historical happenings," but rather, that these are often less explicit and less abstract than those applied by the sociologist. ${ }^{16}$

The distinction between the sociologist and historian is not a distinction between a deductive and an inductive approach. Rather, the sociologist is trained to think in terms of theoretical issues and concepts and to select specific empirical subjects and evidence accordingly. Optimally, this selection is deliberate, originating in an understanding of the relevant theoretical literature that has already postulated connections (causal or otherwise) among various phenomena. As Robert Merton has noted:

Exposure to such penetrating sociological minds as those of Durkheim and Weber helps us to form standards of taste and judgment in identifying a good sociological problem-one that has significant implications for theory-and to learn what constitutes an apt theoretical solution to the problem. ${ }^{17}$

\section{SOME BASIC METHODOLOGICAL DECISIONS}

A preoccupation with analytical generalization has led historical sociologists in two directions. Some scholars have undertaken systematic reevaluations of established theories. Relying on new data sources or fresh

${ }^{14}$ For further discussion of this point, see below pp. 164-67.

${ }^{15}$ Smelser, Essays in Sociological Explanation, p. 35.

16 Ibid. Thrupp has observed that: "ideally, they [historians] aim at becoming familiar with all aspects of the culture of a period before singling out particular matters for investigation. This gives one hunches as to the points at which events, ideas, structures of relationship, are taking a genuinely new turn, modifying or breaking with regularities and directions set in the past. Hunches are tested by wide general reading and some check of the primary sources of the preceding period. But these are counsels of perfection that in practice are often bypassed as too laborious." Although seldom implemented in its ideal form, this conception nonetheless influences the way historians proceed in selecting an empirical problem. Sylvia L. Thrupp, "History and Sociology: New Opportunities for Cooperation," reprinted in Grew and Steneck, eds., Society and History, p. 299.

${ }^{17}$ Merton, Social Theory and Social Structure, p. 36. 
consideration of existing evidence, scholars such as Tilly and Moore have imposed strenuous and exacting empirical tests on accepted explanations and in some cases, found them wanting. ${ }^{18}$ In and of itself, theory-testing has produced important revisions in sociological knowledge.

Ultimately, however, most historical sociologists have sought to develop new theories capable of providing more convincing and comprehensive explanations for historical patterns and structures. These explanations for historical phenomena, applied to a single case, a limited class of cases, or universally, can be reached by methods that are primarily inductive, deductive, or some combination of the two. Moreover, the explanatory intentions of generalizing statements may vary, depending on whether causality and/or covariance is being established.

A research strategy also involves the selection of concepts. Like generalizing statements, these concepts can be formulated on various levels of applicability. Sociologists generally work with "concepts of limited applicability" or with universal concepts, for example, the concept of "class" as opposed to the concept of "interest aggregation." 19 The choice of concepts, as well as the theoretical aims of a given endeavor, are indicative of underlying assumptions that the investigator brings, implicitly or explicitly, to the project. "Value relevance," as Weber termed it, represents a central but neglected aspect of methodological procedure. ${ }^{20}$

It is essential to consider not only the type of conceptual and theoretical apparatus employed by the investigator, but also the function this apparatus performs in the research design as a whole. The functional dimension appears most clearly when we consider two related issues: first, the interaction of theories and concepts with historical evidence, and second, the forms of comparison found in historical-sociological research.

${ }^{18}$ The testing of established theories forms a central preoccupation in Tilly's work. He has written: "When I began my long inquiry into conflict, protest and collective action, I hoped to accumulate the evidence for a decisive refutation of the Durkheimian line." Charles Tilly, "The Uselessness of Durkheim in the Historical Study of Social Change," Center for Research on Social Organization, University of Michigan, Working Paper No. 155, March 1977, p. 19. Moore, Social Origins, ch. vii, viii, ix.

${ }^{19}$ Reinhard Bendix and Guenther Roth, Scholarship and Partisanship: Essays on Max Weber (Berkeley, Los Angeles and London: University of California Press, 1971), p. 218. Bendix defines concepts of limited applicability as "concepts that are usefully applied to more than one society for a period whose approximate beginning and end are themselves an object of research." For an exceptionally lucid discussion of sociological concepts, see Reinhard Bendix, "Comparative Sociological Studies," in Transactions of the Fifth World Congress of Sociology, Washington, D. C., 2-8 September 1962 (Louvain, Belgium: International Sociological Association, 1964).

${ }^{20}$ The moral and political concerns of historical sociologists deserve careful consideration which cannot be undertaken here. A provocative discussion of these problems can be found in Reinhard Bendix, Social Science and the Distrust of Reason (Berkeley and Los Angeles: University of California Press, 1951). On this subject, see also Immanuel Wallerstein, "Introduction," The Modern World-System (New York: Academic Press, 1974) and The Capitalist World-Economy (Cambridge, England: Cambridge University Press, 1977), pp. x-xii. 


\section{HISTORY MEDIATED BY THEORY}

How do historical sociologists select, organize, and interpret historical evidence? Proceeding with a more explicit formal conceptual and theoretical framework than most historians have, sociologists handle empirical material in ways that relate to their analytical preoccupations. More specifically, two types of approach to history can be discerned, depending on the investigator's reliance on theory or concepts as the principal heuristic device.

One major approach can be discerned among historical sociologists whose central concern is to formulate theoretical statements or models, often of a causal nomothetic variety. For these scholars, history is mediated by theory. Neil Smelser has described with exceptional clarity the methodological foundations of one variant of this approach, applied in his study Social Change in the Industrial Revolution:

The thing that set my research off most from what many historians do is that I approached the Industrial Revolution as a case illustration of an explicit, formal conceptual model drawn from the general tradition of sociological thought. . . It was this abstract, analytical model. . that generated problems for me, not the period of the Industrial Revolution as such. I might well have chosen industrial change in another country and another period; or even an instance of rapid social change in which industrialization did not occupy a significant place. ${ }^{21}$

As the subtitle of the study indicates, Smelser is principally interested in "an application of theory to the British cotton industry." The middle-range theory he uses to analyze working-class protest, organization, and family structure has been formulated deductively on the basis of Parson's general theory of action. ${ }^{22}$ More specifically, Smelser develops a seven-step sequence that purports to offer an analysis of the causes and consequences of structural differentiation and social movements in industrializing societies. He applies the model to two structural contexts--industry and the family-and contends that popular protest in the first half of the nineteenth century represented "symptoms of disturbance" attributable to changes underway within the family.

The model provides, in Smelser's imagery, "empty theoretical boxes." The task of the investigator is to fill the empty boxes with empirical evidence, thus confirming or disproving the theory's utility for interpreting history. The interplay between history and theory has been described by Smelser:

${ }^{21}$ Neil J. Smelser, "Sociological History: The Industrial Revolution and the British Working-Class Family," in Smelser, Essays in Sociological Explanation, p. 77. This important essay originally appeared in The Journal of Social History, 1 (1967), pp. 17-36, and is also reprinted in M.W. Flinn and T.C. Smout, Essays in Social History (Oxford: At the Clarendon Press, 1974), pp. 23-38.

22 Smelser, Social Change, Ch. II. 
To determine this utility [of the model], the investigator must turn to the laborious tasks of historical analysis. He must translate the general concepts and relations into historically specific terms. He must track down the best historical sources to ascertain the degree to which the hypothesized connections among events hold. He must render as careful and objective a judgement as possible on whether the historical record lends support to the relations posited in the model. And if history proves embarrassing by not conforming to the model sequences, he must be prepared to return to the model and modify it in the light of his researches. ${ }^{23}$

Two decades after its publication, Smelser's book owes its continuing significance to its meticulous research as well as the controversial methodology. ${ }^{24}$ The procedure followed in this study, with its explicitly deductive orientation and causal nomothetic propositions, is remote indeed from the ideal conception of the historian's craft. But Smelser's approach has a long and illustrious sociological lineage, extending from Marx in the nineteenth century to Parsons in the twentieth century.

Another sociologist who shares Smelser's preoccupation with theoretical models is Immanuel Wallerstein. Wallerstein introduces his study, The Modern World-System, with an arresting analogy:

I was inspired by the analogy with astronomy which purports to explain the laws governing the universe, although (as far as we know) only one universe (and likewise one world-system) has ever existed. What do astronomers do? As I understand it, the logic of their arguments involves two separate operations. They use the laws derived from the study of smaller physical entities, the laws of physics, and argue that (with perhaps certain specified exceptions) these laws hold by analogy for the system as a whole. Second, they argue a posteriori. If the whole system is to have a given state at time $y$, it most probably had a certain state at time $x .^{25}$

The search for causal nomothetic propositions leads Wallerstein to "concrete" historical investigation, "just as in cosmology the only road to a theory of the laws governing the universe is through the concrete analysis of the historical evolution of this same universe." 26 And like the astronomer, Wallerstein proceeds with his investigation on the assumption that what he is studying constitutes a system in which all the constituent parts are functionally related. But in history, unlike astronomy, the existence of such a system cannot be taken as a given. Wallerstein's model rests, therefore, on an a priori assertion borrowed from the natural sciences and applied, more or less arbitrarily, to the sphere of international economic relations.

Stripped of its astronomical imagery, Wallerstein's model of a "worldsystem" is a formal deductive one whose two hypostases (the "worldempire" and "world-economy") are, by his own acknowledgement, de-

${ }^{23}$ Smelser, "Sociological History," in Flinn and Smout, eds., Essays in Social History, p. 28.

${ }^{24}$ For a recent critical discussion of Smelser's study, see Michael Anderson, "Sociological History and the Working-Class Family: Smelser Revisited," Social History 3 (October 1976).

${ }^{25}$ Wallerstein, The Modern World-System, p. 7.

26 Wallerstein, The Capitalist World-Economy, p. 7. 
rived "logically" and not empirically. ${ }^{27}$ Like Smelser, he has drawn upon general sociological theory (in this case, a blend of Marxism and functionalism) for his model. Unlike Smelser, however, who formulates a middlerange theory of social change, Wallerstein offers a model with universal applicability, purporting to explain global developments from the "Neolithic Revolution" to recent times. ${ }^{28}$ In the first of several anticipated volumes, Wallerstein examines the origins of capitalism in sixteenth-century Europe - a region the author views as the core of an expanding "world-economy." The distinctiveness of this analysis lies in its global perspective and the conception of capitalism as arising out of a distribution system that has international dimensions. ${ }^{29}$

The model of the world system serves as an "empty box" to be filled with historical material. But what criteria guide the selection of empirical evidence needed to test a theory of such amplitude? Wallerstein proposes to rely on analogy and a posteriori reasoning, procedures adopted from the natural sciences. To argue by analogy is to argue that any constituent of the system will be governed by "laws [that] hold by analogy for the system as a whole." 30 A posteriori reasoning assumes that a prior condition of the system can be derived from its subsequent state, thus reversing the customary direction of historical inquiry. Instead of extrapolating the present state of affairs from the past, the past is extrapolated from the present. Both of these procedures take for granted that history is governed by fixed and immutable laws. The very proposition that requires testing is thus embedded in the methodology.

\section{"ILLUSTRATIVE" AND "ANALYTICAL" USES OF COMPARISON}

In contrast to Smelser's intrasocietal focus, Wallerstein's study belongs to the category of macrosociological research. Relying on one or several units of analysis ranging from entire societies, civilizations, or a transnational unit, macrosociological studies such as Wallerstein's characteristically make comparison a central feature of the research strategy.

Generally speaking, comparison--or the juxtaposition of equivalent units - takes two forms in historical-sociological research. ${ }^{31}$ In the first or "analytical" type, the main point of comparison is between or among equivalent units. The comparison involves an identification of independent

${ }^{27}$ Ibid., p. 5.

${ }^{28}$ Ibid., p. 158.

${ }^{29}$ Robert Brenner, "The Origins of Capitalist Development: A Critique of Neo-Smithian Marxism," New Left Reriew, 104 (July-August 1977), discusses this aspect of Wallerstein's argument.

${ }^{30}$ Wallerstein, The Modern World-System, p. 7.

${ }^{31}$ This conceptualization of approaches to comparison is drawn partly from an unpublished seminar paper by Donald Reneau, "Comparative Historical Analysis: A Critique of Sociology 242A." Berkeley. California. Fall 1978. 
variables that serve to explain common or contrasting patterns or occurrences. ${ }^{32}$ The investigator juxtaposes equivalent units with each other in order to discern regularities that might provide explanatory generalizations. In the second or "illustrative" type, the main point of comparison is between equivalent units on the one hand and a theory or concept on the other. This variant evaluates individual units not in relation to each other but in relation to a basic theory or concept applicable to all of them. The diagram below illustrates the difference between "analytical" and "illustrative" forms of comparison.

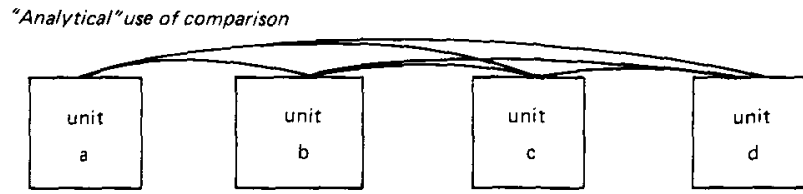

"I/lustrative" use of comparison

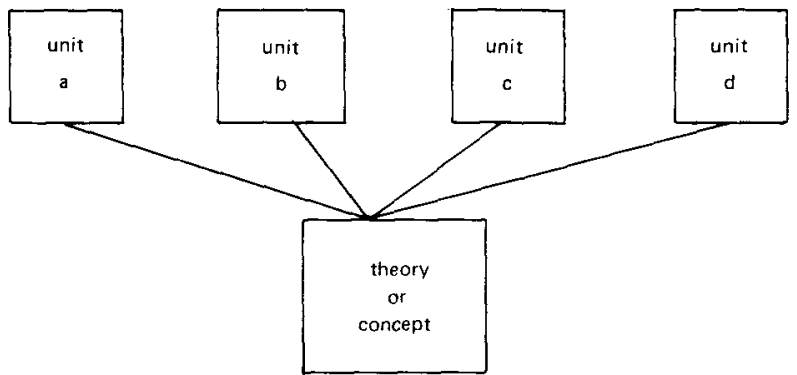

FIGURE 1. Forms of Comparison

The unit of analysis in Wallerstein's study is a single transnational system composed of many individual parts and stages. According to the author, "within such a framework. . we can fruitfully make comparative analyses- of the whole and of parts of the whole." 33 But the comparison undertaken in this study seldom entails an analytical juxtaposition of equivalent units such as nations, social classes or state organizations.

\footnotetext{
32 Marc Bloch has noted the importance of comparing contrasting as well as similar phenomena: "But let us beware of a misunderstanding from which the comparative method has only too frequently suffered. Too often people have believed or affected to believe that its only aim is to search for similarities... . On the contrary, the comparative method, rightly conceived, should involve specially lively interest in the perception of the differences, whether original or resulting from divergent developments from the same starting point." Marc Bloch, Land and Work in Medieval Europe. Selected Papers by Marc Bloch, trans. by J.E. Anderson (Berkeley and Los Angeles: University of California Press, 1967), p. 58.

${ }^{33}$ Wallerstein, The Capitalist World-Economy, p. 36.
} 
Instead, Wallerstein uses comparison primarily to identify and elucidate the relative position and function of constituent elements in the worldsystem. Various equivalent units are juxtaposed not to each other but to a theoretical model (the world-system with its core, semi-periphery and periphery). This use of comparison serves primarily to illustrate a preestablished model.

\section{HISTORY MEDIATED BY CONCEPTS}

At first glance, the works of Charles Tilly and Reinhard Bendix appear to have little in common. Judged by the choice of analytical unit, sources, and evidence, these two prolific scholars have pursued widely disparate research strategies. Yet they stand closer to the historian's craft than most practitioners of historical-sociological research, and they share an analogous approach to history and comparison.

These similarities become apparent when we consider Tilly's writings on collective violence (his contribution to The Rebellious Century 1830-1930 and related essays), ${ }^{34}$ together with Bendix's studies, Nation-Building and Citizenship and Kings or People. ${ }^{35}$ In these works, concepts rather than theories or models provide the principal heuristic device. It is not that Tilly and Bendix have no theoretical aims, for both authors seek in varying ways to test and formulate generalizing statements about historical phenomena. But in contrast to Smelser and Wallerstein, they rely primarily on concepts to facilitate the selection, organization, and interpretation of empirical material. Thus, Tilly's concept of collective violence and Bendix's concept of authority function much like Smelser's model of social change and Wallerstein's model of the world-system. These key concepts provide the medium for handling historical evidence.

In the introduction to The Rebellious Century, the Tillys describe their analytical objectives:

In short, the evidence necessary for checking different theories of "breakdown" and "solidarity" against the modern experiences of west European countries exists; it will yield to people who are willing to do the hard work of accumulating it. At a minimum, we can examine broad questions of covariation: do crime and collective violence go together (as most breakdown arguments suggest)? Do strikes and collective violence tend to draw on the same groups of workers (as some versions of the solidarity argument insist)? In fact, it is possible to be a good deal more demanding than that for some periods, some kinds of structural change, some forms of conflict, and some varieties of disapproved behavior ${ }^{36}$

${ }^{34}$ Charles Tilly, "Collective Violence in European Perspective," in Hugh Davis Graham and Ted Robert Gurr, eds., A History of Violence in America: Historical and Comparative Perspective (Washington, D. C.: U.S. Government Printing Office, 1969); Charles Tilly, "Revolutions and Collective Violence," in Fred I. Greenstein and Nelson Polsby, eds., Handbook of Political Science (Reading, Mass.: Addison-Wesley, 1974).

${ }^{35}$ Reinhard Bendix, Kings or People. Power and the Mandate to Rule (Berkeley, Los Angeles, and London: University of California Press, 1978).

36 Tilly, Tilly and Tilly, The Rebellious Century 1830-1930, p. 11. 
By sociological standards, these are modest aims, confined to the testing of established theories using new evidence and the formulation of generalizations concerning covariance. These generalizations, scrupulously labelled "analyses" or "statements" rather than "theories" or "models," 37 are derived inductively, from empirical data.

All of this appears to conform to the time-honored research procedures favored (at least in principle) by historians. But the resemblance is only partial. In The Rebellious Century and related essays, concepts provide the "empty boxes" for quantifiable empirical data. It is not merely the reliance on concepts but also the nature of these concepts that has methodological bearing on Tilly's work. The central focus of The Rebellious Century is the concept of "collective violence," defined by the authors as follows:

The violent events analyzed systematically in this book. . include actions in which at least one formation (a group acting together) above a certain size--twenty or more in Germany, fifty or more in Italy or France-took part, and in which at least one group seized or damaged persons or objects not belonging to itself. ${ }^{38}$

These specifications were required to ensure the serviceability of the universal concept in actual data collection. But the concept retains a high degree of imprecision, conceivably incorporating such diverse occurrences as a political demonstration, an economic strike, a pogrom, and a drunken brawl. The breadth of the concept produces data that are both massive and undifferentiated. Much of Tilly's analysis, therefore, is directed toward the disaggregation of these data by means of various classificatory schemes (e.g., subdividing collective action into competitive, proactive and reactive types). ${ }^{39}$

The Rebellious Century is an explicitly comparative work. Accompanying the case studies of three countries (France, Italy, and Germany) are several comparative chapters that evaluate the empirical findings, first in relation to general analytical statements (concerning the covariance of collective violence with industrialization, urbanization, struggles for state power) and second, in relation to various typologies of collective action and collective violence ${ }^{40}$ Elements of both "analytical" and "illustrative" uses of comparison can be discerned here. The experiences of each country are juxtaposed against the others in order to establish common patterns. But all of this proceeds within the framework of a conceptual apparatus which itself often serves as the principal focus for the handling of comparative material.

${ }^{37}$ Ibid., p. 244, for remarks on this point.

38 Ibid., p. 312.

${ }^{39}$ Ibid., p. 250 . For further discussion of these typologies, see Charles Tilly, "Collective Violence in European Perspective," in Graham and Gurr, op. cit., and "Revolutions and Collective Violence," in Greenstein and Polsby, op. cit.

40 Ibid., Chs. 56. 
Bendix also relies on concepts as the primary heuristic device. In NationBuilding and Citizenship and Kings or People, concepts such as "authority" and "legitimacy" provide the framework for examining the historical development of political institutions. These concepts, resembling Weber's ideal types, are by their very nature more elusive than Tilly's terms which refer to concrete actions rather than the intangible realm of ideas and relationships.

Bendix's concepts, like Tilly's, are universally applicable, a circumstance that Bendix views as a potential obstacle to empirical research. In NationBuilding and Citizenship, Bendix has addressed this problem and described his own research strategy:

Universal concepts such as the division of labor require specifications that will bridge the gap between concept and empirical evidence, but such specifications have a limited applicability. . .It is more illuminating to learn in what ways the division of labor in one social structure differs from that in another than to reiterate that both structures have a division of labor. These considerations point to a persistent problem in sociology. Concepts and theories are difficult to relate to empirical findings, while much empirical research is devoid of theoretical significance. . The following studies attempt to steer a course between this Scylla and Charybdis by relying upon familiar concepts as a base line from which to move forward. ${ }^{41}$

Finding the correct level of generality for concepts represents a major methodological preoccupation in Bendix's research. Since history is mediated through concepts, it is essential to establish categories that are neither too precise nor too comprehensive. Bendix attempts to resolve this difficulty by imposing specifications on universal concepts, limiting their applicability. The notion of "authority," so central to Bendix's work, is narrowed in Nation-Building and Citizenship to encompass specific types of authority relations (e.g., "administrative," "private," "public"). Bendix’s analytical contribution rests partly on a disaggregation of highly generalized concepts and their application to specific historical contexts, a trait we have noted in Tilly's work as well. Through the construction of typologies, both authors come to grips with terminology too broad to provide a meaningful analysis of particular historical situations or phenomena. In their penchant for classification based on general concepts, Bendix and Tilly stand in the Weberian tradition.

Bendix explicitly avoids drawing causal inferences from comparative material. His methodological objection to such inferences is based on the conviction that the "number of cases is too small and the number of variables too large" in macrosociological study to warrant causal statements. ${ }^{42}$ "Comparative analysis," he observes in the introduction to Kings or People, "should sharpen our understanding of the contexts in which

${ }^{41}$ Bendix, Nation-Building and Citizenship. p. 249.

42 Reinhard Bendix, "The Mandate to Rule: An Introduction," Social Forces 55: 2 (December 1976), p. 246. 
more detailed causal inferences can be drawn." ${ }^{43}$ Thus, Bendix does not rule out the possibility that causal explanation might eventually be undertaken, but confines his own study to an investigation and comparison of specific historical contexts. It is this elaboration of contexts, together with the reliance on certain generalized concepts, that lends Bendix's studies a distinctly historicist tone.

Whereas many sociologists search for historical uniformity, Bendix has shown an abiding interest in the way societies differ in their responses to fundamental problems. This emphasis on idiographic aspects of historical development lies at the heart of Bendix's comparative treatment of five major societies over a period of many centuries. Describing his comparative method in Kings or People, Bendix has observed:

I ask the same or at least similar questions of very different contexts and thus allow for divergent answers. Structures of authority in different countries do vary; societies have responded differently to challenges prompted by advances from abroad. The value of this study depends on the illumination obtained from the questions asked and from a sustained comparative perspective. ${ }^{44}$

Bendix's approach to comparative analysis has a functional component, for he examines recurrent dilemmas that face societies with similar types of rule (kingship, for example) or with comparable international positions of relative back wardness. ${ }^{45}$ Comparison among societies serves to illuminate the various resolutions of these dilemmas - often in contrasting ways-in various national and temporal contexts. In Bendix's "analytic" use of comparison, concepts function as bright threads that, when woven into the fabric of historical narrative, allow the author to identify general patterns while at the same time preserving a sense of historical particularity.

Barrington Moore's Social Origins of Dictatorship and Democracy illustrates how various methodological elements can be combined in historicalsociological research. Moore introduces his macrosociological study with a metaphor, comparing generalizations about history to a "large-scale map of an extended terrain, such as an airplane pilot might use in crossing a continent." ${ }^{46}$ In his search for causal generalizations about political outcomes, Moore shares the theoretical focus discerned in the work of Smelser and Wallerstein. But Moore is unwilling to formulate invariant laws and

${ }^{43}$ Bendix, Kings or People, p. 15.

$44 \mathrm{Ibid}$. Elsewhere Bendix has written: "By means of comparative analysis I want to preserve a sense of historical particularity as far as I can, while still comparing different countries. Rather than aim at broad generalizations and lose that sense, I ask the same or at least similar questions of divergent materials and so leave room for divergent answers. I want to make more transparent the divergence among structures of authority and among the ways in which societies have responded to the challenges implicit in the civilizational accomplishments of other countries." Bendix, "The Mandate to Rule," p. 247.

${ }^{45}$ See, for example, ch. 7, 8 in Bendix, Kings or People.

${ }^{46}$ Moore, Social Origins, p. xiv. 
his generalizations linking class structures and class relations to political outcomes cannot be reduced to formulas or models.

As the opening metaphor suggests, Moore's analytical statements resemble the map of a terrain on which the principal sites (or independent variables) have been delineated. The author's strategy is to identify independent variables whose combination and permutation under specified historical circumstances is said to culminate in one of three types of political arrangement (democracy, fascism, communism).

The lack of a rigorous formulaic approach to generalizations lends a partially inductive tone to Moore's research. In fact, Social Origins displays a blend of deductive and inductive elements. ${ }^{47} \mathrm{On}$ the one hand, the author adopts explicit a priori assumptions that confer explanatory value on some factors (e.g., social classes and relations) and minimize or ignore the significance of others (e.g., ideology, culture, international relations). Within these parameters, Moore sifts through the available secondary literature, evaluating established interpretations and collecting empirical evidence until a new synthesis has been inductively achieved.

Social Origins is organized around six detailed case studies and several analytical chapters, a format also adopted by Bendix in Kings or People. Notwithstanding the many methodological and substantive differences between these two books, they share a similar use of comparison that is "analytical" in form and functionalist-albeit in different ways-in content. Moore takes the approach that societies confront common problems at comparable stages of development and through an "analytical" use of comparison, he contrasts the various routes that societies have taken in coming to grips with these problems and the long-term consequences of their solutions. Bendix rejects the view of history inherent in Moore's approach, but his use of comparison also has a functionalist component, as noted above. Whereas Bendix inquires into the way societies have contended with certain recurring dilemmas, Moore focuses on "the ways in which the landed upper classes and the peasants reacted to the challenge of commercial agriculture," 48 and, more generally, on the way societies have succeeded or failed in eliminating the obstacles to capitalist development.

When sociologists turn to the study of history, they bring with them a distinctive disciplinary orientation. I have suggested that the sociologist's view of history is mediated either by theories or by concepts that are applicable to more than one case. One type of sociological history, exemplified by Smelser's Social Change in the Industrial Revolution and Waller-

\footnotetext{
${ }^{47}$ In the Preface to Social Origins, Moore observed: “Nevertheless there remains a strong tension between the demands of doing justice to the explanation of a particular case and the search for generalizations, mainly because it is impossible to know just how important a particular problem may be until one has finished examining all of them." Ibid., p. xvii.

${ }^{48}$ Moore, Social Origins, p. xvii.
} 
stein's The Modern World-System, uses a theory or model, often of a deductive causal nomothetic variety, as the medium for selecting, organizing, and interpreting historical evidence. Another variant of this approach can be found in Moore's Social Origins. Although Moore also depends on a theoretical apparatus for conceptualizing history, he avoids invariant laws and formulates causal statements that are only partly deductive.

In a second category of historical-sociological research, the interpretation of history is mediated by concepts. Tilly's work on collective violence and Bendix's studies of authority illustrate this approach in which concepts rather than theories or models function as the main heuristic device. Among practitioners of the second type, analytical generalizations tend to be inductive rather than deductive, and instead of causal nomothetic propositions, there are at most statements of covariance.

Historical sociologists use both "analytical" and "illustrative" forms of comparison. The "analytical" form, in which the main point of comparison is between or among equivalent units, can be discerned in the work of Moore, Tilly and Bendix. The "illustrative" form, justaposing equivalent units not in relation to each other but in relation to a theory or concept applicable to all of them, is applied by Wallerstein and, to some extent by Tilly. The two forms of comparison perform different functions in a research strategy. "Analytical" comparison serves to identify independent variables that account for similar or contrasting patterns, whereas "illustrative" comparison focusses on correspondences between a unit or units of analysis and a theory or concept.

I have argued that approaches to history and comparison offer fundamental insight into the disciplinary perspective of sociologists who study history and, more specifically, into the way various practitioners have resolved key problems in historical-sociological research. It remains, finally, to consider recent trends and future prospects in the field of historical sociology.

Over the past several decades, historical-sociological research has displayed a high degree of continuity. Works as removed from each other in time and substance as Smelser's Social Change in the Industrial Revolution (1959) and Wallerstein's The Modern World-System (1974) exhibit common methodological features indicative of deeply etched disciplinary conceptions of sociological history. The persistence of basic methodological configurations is particularly noteworthy in light of two important developments: the growing application of quantitative methods in historical investigation and the unprecedented involvement of sociologists in original historical research (including the use of archival sources). But how do quantitative techniques and original historical research influence the theoretical and conceptual framework of a sociologist? Questions of this sort are bound to arise whenever a new method is introduced into a discipline, 
and the application of quantitative methods has indeed generated a lively and controversial discussion. ${ }^{49}$ The impact of original historical research undertaken by sociologists, however, has largely been ignored.

Until recently, the sociological study of history was based primarily on secondary literature. This reliance on secondary sources freed historical sociologists from laborious and time-consuming investigation of undigested primary data, making it possible to undertake sociological analysis at a high level of generality. Yet this same reliance inevitably limited subject matter to the range already explored by historians, economists, anthropologists, demographers, and others, excluding at the very outset exploration of many questions for which monographic literature was as yet inadequate. ${ }^{50}$ Furthermore, as long as sociological analysis rested on an empirical foundation laid by others, the evidence might be incomplete or inaccurate. $^{5 t}$

Tilly's work, beginning with The Vendée, led the way in enlarging the sociologist's role from that of a progenitor of theories and concepts into a craftsman, who collects and pieces together empirical evidence for the first time. Scholars such as Smelser, Bendix, and Moore have, on occasion, also made use of published primary sources in their research, ${ }^{52}$ but they have seldom attempted to break new historical ground. It is therefore noteworthy that in recent years sociologists have begun to participate in a dual process, involving both a conventional historical investigation (uncovering, sorting, and evaluating raw historical data) and a general sociological analysis. ${ }^{53}$

${ }^{49}$ Lorwin and Price, eds., The Dimensions of the Past; Moore, "Strategy in Social Science," in Moore, Political Power and Social Theory.

${ }^{50}$ The recent involvement of sociologists in original historical research is closely connected to the growing interest in subjects that could not be pursued on the basis of existing monographic or even published primary sources. For this reason, much of the primary research by historical sociologists concerns the study of social movements and collective action among lower class groups, subjects long neglected by historians and sociologists alike. Further advances in these areas required new and original research using archival materials and other primary sources.

${ }^{51}$ Bendix raises this problem explicitly in the Introduction to Kings or People, p. 16: "Comparative studies depend on qualitative judgments and illustrative uses of evidence. I have relied on the judgments of historians but primarily on my own sense of how much illustrative material is needed to give the reader a vivid impression of the point to be made. In practice, I have found it necessary to make the best judgments I can and then warn the reader, as I do here, that these judgments remain tentative and may have to be modified by further scholarly work or by the judgments of scholars more expert in a given field than I can hope to be."

52 For example, see Smelser's Social Change in the Industrial Revolution; Bendix's Work and Authority in Industry, Ch. 2; Moore's Terror and Progress and Injustice. The Social Bases of Obedience and Revolt (White Plains, N.Y.: M.E. Sharpe, 1978).

${ }^{53}$ Research of this type, much of it by younger scholars, has only recently begun to appear. See Ronald Aminzade, "Breaking the Chains of Dependency: From Patronage to Class Politics, Toulouse, France, 1830-1872," Journal of Urban History, 2:4 (August 1977); Idem, "The Transformation of Social Solidarities in Nineteenth-Century Toulouse," in John Merri- 
The trend toward original historical research undoubtedly has a salutary effect on the field of historical sociology as a whole. It upgrades the standard and techniques of research, instills a more sensitive attitude toward empirical material, and, what is more important, ensures a closer correspondence between the sociological imagination and historical evidence. Nevertheless, one should not mistake this trend for a metamorphosis of sociologists into historians. This brings me back to the problem that served as the point of departure - the intrinsic methodological divergences between the disciplines of sociology and history. It is striking that historical sociologists, while shifting to new sources and evidence, have continued to employ specific types of explicit, abstract generalizing concepts and theories in historical analysis. Even though sociologists have adopted some of the historians' tools, they show little sign of relinquishing their own methods of approaching history and comparison. For the foreseeable future, a preoccupation with theories and concepts will continue to dominate and shape research strategies in the sociological study of history. The contribution of historical-sociological research lies precisely in this distinctive commitment to an analysis of structures and events across temporal and national boundaries.

man, ed., Consciousness and Class Experience in Nineteenth-Century Europe (New York: Holmes and Meier: 1979); Idem, "The Development of the Strike in Mid-Nineteenth-Century Toulouse," Social Science History, 3: 1 (January 1980); Victoria E. Bonnell, "Radical Politics and Organized Labor in Pre-Revolutionary Moscow, 1905-1914," Journal of Social History, 12:2 (March 1979); Idem, "Trade Unions, Parties and the State in Tsarist Russia: A Study of Labor Politics in St. Petersburg and Moscow," Politics and Society, 9:3 (1979) David Mandel, "Petrograd Workers in 1917," 2 vols., Ph.D. diss., Department of Sociology, Columbia University, 1977; Allan Sharlin, "From the Study of Social Mobility to the Study of Society," American Journal of Sociology, 84:7 (1979) Jonathan M. Wiener, "Planter-Merchant Conflict in Reconstruction Alabama," Past and Present, 68 (August 1975); Idem, Social Origins of the New South: Alabama, 1860-1885 (Baton Rouge: Louisiana State University Press, 1978). 